\title{
MORPHOLOGICAL CHANGES IN THE VASCULATURE OF THE OVARIES OF THE SOW AS INFLUENCED BY AGE FROM BIRTH TO 8 YEARS
}

\author{
HARPAL S. BAL AND ROBERT GETTY \\ Department of Veterinary Anatomy, Iowa State University, \\ Ames, Iowa, 50010 U.S.A.
}

(Received 10th Fuly 1969)

Summary. Significant changes take place in the vasculature of the ovaries at different age periods in the sow: at birth, arteries, veins and lymphatics were seen in the medullary region of the ovaries. Rapid growth of the tunica media of arteries took place between 1 and 2 months of age. By 6 months of age, the tunica intima, media, and adventitia were clearly differentiated. By 6 months to 3 years, the medullary vessels exhibited splitting of the internal elastic lamina and the start of intimal thickening. By 3 to 8 years, the arteries of the ovarian tissue presented intimal thickening which appeared in two noticeable forms and progressed with advancing age in a number of vessels.

In medium-sized vessels, it was of a uniform nature affecting the whole tunica intima. At approximately 5 years of age, the intimal thickness equalled almost half of the cross-sectional thickness of the arterial wall of the affected vessels.

In the 8-year age group, the tunica intima approximated to two-thirds of the width of cross-section of the entire arterial wall of the affected arteries.

In the larger vessels of the medulla, the intimal thickening was not uniform, appearing in the form of plaques in some areas of the arterial walls and diffuse in others.

Gollagenous tissue also increased in the walls of the arteries with advancing age but no lipid or calcium deposition was observed.

\section{INTRODUGTION}

A study to determine the age changes in the ovarian tissue of the sow was initiated as part of the gerontological project in this Department.

Changes in the ovarian vasculature, as in ovarian structure, occur both with age and under the influence of gonadotrophic hormones during the cycle. There is proliferation of arterioles and capillaries which supply the growing follicles as well as the corpus luteum. Attention has, therefore, been focused in this investigation on the morphological changes which take place in the arteries of the sow's ovary during growth and as influenced by age. 
Many reports appear in the literature about the effect of age on the arteries of man and laboratory animals. In the pig, the thickening of the tunica intima of the arteries has been reported in recent years by Gottlieb \& Lalich (1954), Skold \& Getty (1961), French, Jennings, Poole, Robinson \& Florey (1963), and Skold, Getty \& Ramsey (1966), and other authors. Most of these studies have been of the aorta and the coronary arteries in swine. In addition, Getty (1965a, b, 1966a, b) reported on spontaneous lesions in all of the major blood vessels of the hog and dog. In man, studies have largely concerned the effect of age on the coronary arteries and their branches, the terminal branches of the abdominal aorta and the vascular supply to the brain.

An attempt has been made to examine the blood vessels of the ovaries from the 1st post-natal day to the age of 8 years. The descriptions have been based on month to month observations of the ovarian arteries to the age of 4 months, and at approximately half-year intervals from 6 months to 8 years of age.

\section{MATERIALS AND METHODS}

The ovarian tissue samples were obtained from sows for which well-documented breeding, age, and dietary records were kept in this Department. Ovaries of forty-three sows, ranging in age from 1 day to 8 years, were utilized for the study. The animals were in normal health as observed by the usual standards of examination, supplemented by the breeding records. They continued to ovulate, even at the age of 8 years, although litter size decreased with age.

The animals were killed by electrocution and exsanguinated immediately after death by exposing and cutting the axillary artery and vein. As soon as the bleeding ceased, the animals were eviscerated and the ovaries, both right and left, were collected and fixed in $10 \%$ buffered formalin solution. Blocks of the ovarian tissue were made by embedding them in paraffin according to usual procedures. Sections, $6 \mu$ in thickness, were stained with the following stains:

1. Oil red O with Tween 40 for the detection of fatty substances (Bell, 1959).

2. Haematoxylin and eosin.

3. Gomori's silver impregnation method for reticular fibres (U.S. Armed Forces Institute of Pathology, 1960).

4. Modification of Mallory's triple stain (Crossman, 1937).

5. Liver technique using the combination of Weigert's, Heidenhain's, and van Gieson's stains (Getty, 1945).

Above the age of $4 \frac{1}{2}$ years, von Kossa's stain for calcium salts was used to evaluate the possible deposition of calcium in the ovarian tissue (U.S. Armed Forces Institute of Pathology, 1960).

\section{RESULTS}

One day post-natal to 6 months of age

The ovaries of the day-old pig were tri-lobed (Pl. 1, Fig. 1). In the medullary area, the blood vessels were distinct (Pl. 1, Fig. 2). The arteries had thin walls with an internal elastic lamina consisting of a single layer of elastic tissue. The tunica media of these arteries was composed of approximately two layers of smooth muscle cells arranged in a circular manner. The tunica adventitia was 
demarcated by a very fine layer of elastic tissue. The adventitial tissue was more cellular than fibrous.

In arteries somewhat larger than those described in the preceding paragraph, the cells of the tunica media appeared to be angularly orientated to those of the tunica intima (Pl. 1, Figs. 3a, 3b). The nuclei of the smooth muscle cells seemed to be much larger than those of the smooth muscle cells seen in the tunica media of arteries of normal adult pigs at 6 months of age (Pl. 2, Figs. 4, 4'). In a few vessels, it appeared that endothelial cells were in the process of migration into the tunica media of the arteries.

In the 1- to 2-week-old group, venous sinuses lined with endothelial cells became more conspicuous. The venous sinuses had no distinct wall and their endothelial lining was surrounded by stromal connective tissue (Pl. 2, Figs. 5a, $5 \mathrm{~b})$. Lymphatic sinuses, simulating the venous sinuses, were also present. One method to differentiate between the venous and lymphatic sinuses was to identify the presence of erythrocytes in the venous sinuses.

By 2 to 3 months of age (Pl. 3, Fig. 6), the walls of the arteries in the medulla of the ovaries increased in thickness to three to four times that observed in animals less than 1 month of age. The venous sinuses continued to grow larger in this age period.

The internal elastic lamina of the arteries appeared to be serrated with endothelial cells at right angles to the lamina. Some cells appeared to be migrating into the tunica media. The morphology of the endothelial cells and that of the smooth muscle cells in the tunica media of some vessels appeared to be identical.

In the 4-month-old group, the arteries in the medulla still appeared to be in the process of growth. The number of arterioles around the developing Graafian follicles increased. By 6 months of age, the arteries were clearly demarcated into tunica intima, media, and adventitia.

\section{Six months to 3 years of age}

The blood vessels in this period revealed the following changes: splitting of the internal elastic lamina was noticed in a few large arteries of the medulla and some smooth muscle cells appeared between the split layers of the elastic lamina above the age of 6 months (Pl. 3, Fig. 7). A few large medullary vessels exhibited thickened tunica intima in the form of plaques. Smaller arterioles near the cortex with a wall thickness of 40 to $50 \mu$ showed considerable thickening of the tunica intima. This intimal thickening, unlike that of the larger medullary vessels, was of a more uniform nature. In some of these arteries, the intima constituted one-third the thickness of the total arterial wall (Pl. 3, Figs. $8 \mathrm{a}, 8 \mathrm{~b})$. In some vessels, elastic tissue was seen in the intima. A small colony of vessels can be seen in the parenchyma after the involution of the corpora lutea. The smooth muscle of these vessels was arranged in a longitudinal pattern. The intercellular substance of the walls of these arterioles was rich in elastic tissue which gave an amorphous appearance (PI. 4, Fig. 9).

Three to 8 years of age

Above the age of 3 years, the medullary vessels accumulated more collagen- 
ous fibres in the tunica media and the smooth muscle cells appeared more like fibrocytes. The tunica intima thickened with advancing age. The thickened intima appeared in the form of plaques (Pl. 4, Fig. 10) in some areas and in other areas, it was somewhat diffuse (P1.4, Fig. 11). The internal elastic lamina appeared to be interrupted. Some smooth muscle cells were observed lying obliquely, close to the internal elastic lamina. In the 5-year age group, the intimal thickening was equal to half that of the cross-sectional thickness of the wall of the affected vessels.

In the 6- to 8-year-old group, the intimal thickening of the medullary vessels approximated to half of the arterial wall. There was more collagenous tissue

\section{EXPLANATION OF PLATES}

All sections stained with Heidenhain-Weigert-van Gieson stain except Figs. 1, 3a, 5a and $5 \mathrm{~b}$, which were stained with $\mathrm{H}$ and $\mathrm{E}$.

\section{PLATE 1}

Fig. 1. Tri-lobed ovary of the 1-day-old pig showing the cortex and medulla. $\times 25$. FIG. 2. Blood vessels in the medulla of the ovary of a 1-day-old pig. $\times 100$.

FIG. 3a. Arteries in medulla of a 1-day-old pig showing the disposition of endothelial cells angularly oriented towards the tunica media. Longitudinal section. $\times 250$.

FIG. 3b. Vessels with same features as in Fig. 3a. $\times 400$. Cross section.

\section{PLATE 2}

Fig. 4. Normal medullary vessels of a 6 -month-old pig. $\times 25$.

Fig. 4'. Normal medullary vessels of a 6 -month-old pig. $\times 50$.

Fig. 5a. A venous and a lymphatic sinus composed of fibrous tissue and devoid of smooth muscle fibres in a 2-week-old pig. $\times 250$.

Frg. 5b. A large venous sinus lined with endothelium superimposed upon a fibrous tissue wall of a 6 -month-old pig. $\times 250$.

\section{PLATE 3}

Frg. 6. Arteries in the medulla of the ovary of a $2 \frac{1}{2}$-month-old pig. $\times 100$.

FIG. 7. An artery showing splitting of the internal elastic lamina of a 1-year 7-month-old pig. $\times 250$.

FIG. $8 \mathrm{a}$. Smaller arteries in the cortex of the ovary of a 2-year 5-month-old pig showing thickened tunica intima. $\times 100$.

Frg. 8b. A cortical artery showing thickening of the tunica intima approximating to onethird of the cross-sectional width of the tunica media of a 2-year 5-month-old pig. $\times 250$.

\section{PLATE 4}

Fig. 9. Small arterial colonies of a degenerated corpus luteum showing accumulation of elastic tissue in the tunica media of a $2 \frac{1}{2}$-year-old pig. $\times 100$

Fig. 10. A medullary artery of an 8-year-old pig showing a thickened plaque of the tunica intima. $\times 250$.

FIG. 11. A medullary artery of an 8-year-old pig showing diffuse thickening of the tunica intima. $\times 250$.

FIG. 12. A smaller artery of an 8-year-old pig with thickened intima approximating to two-thirds of the cross-sectional thickness of the arterial wall. The smooth muscle is arranged in two patterns, an inner longitudinal in the tunica intima and an outer circular layer in the tunica media. $\times 250$.

\section{PLATE 5}

Fig. 13. A small artery of an 8-year-old pig showing the same features as in Fig. 12. The tunica intima is very thick, almost occluding the lumen of the artery. $\times 250$.

Fig. 14. A group of small vessels from the ovary of an 8-year-old sow showing the same features as in Figs. 12 and $13 . \times 100$. 
PLATTE I
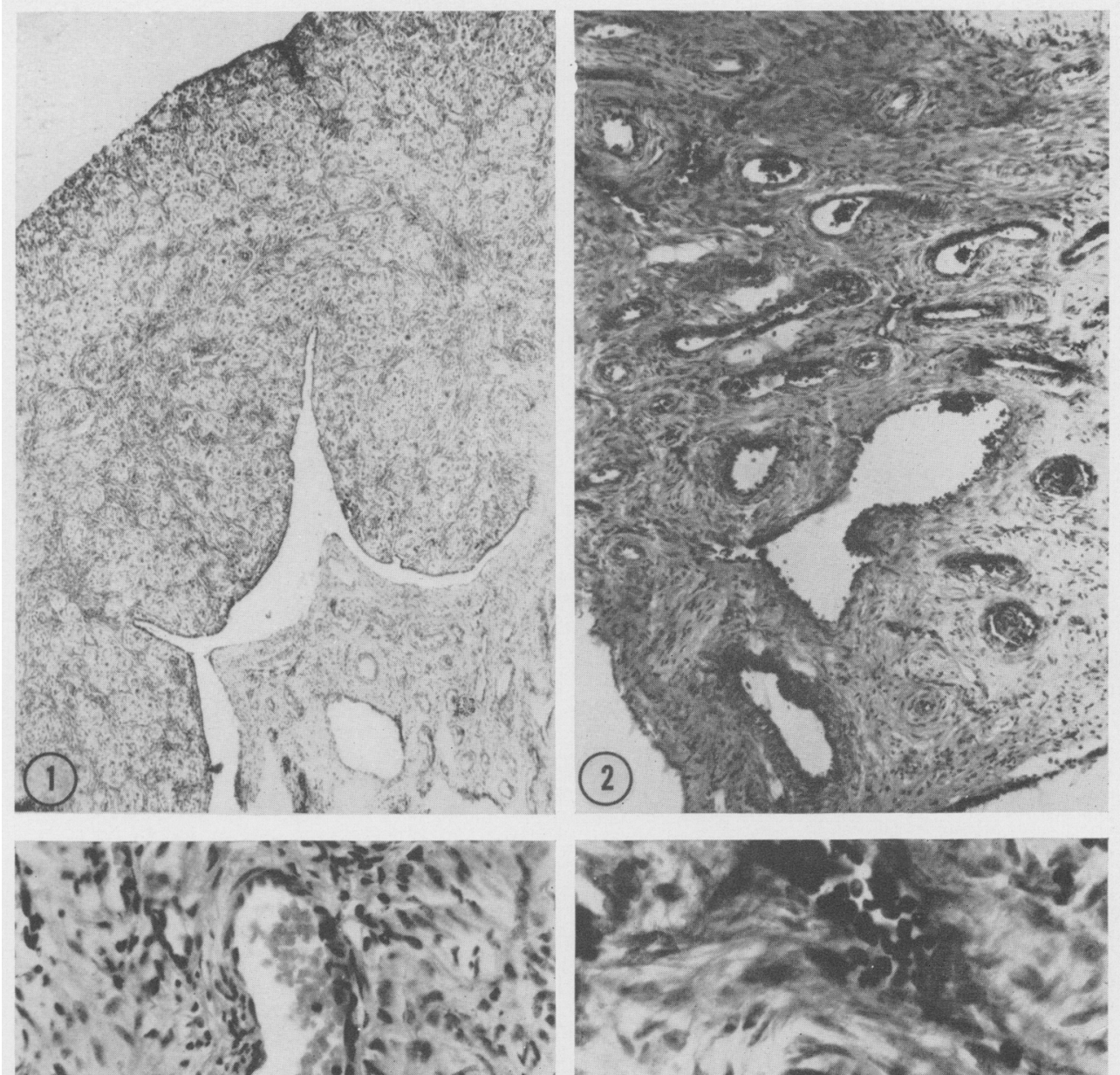

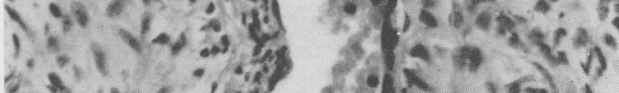

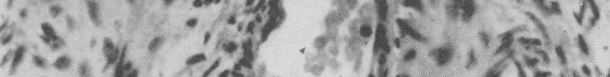

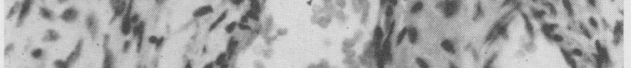

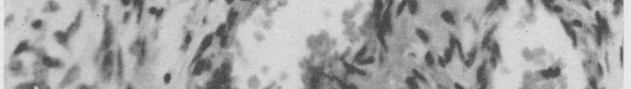

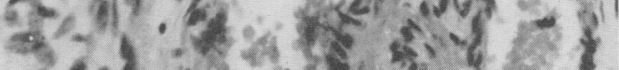

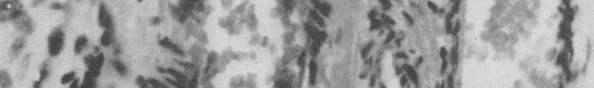

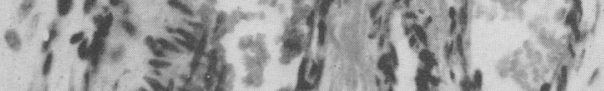

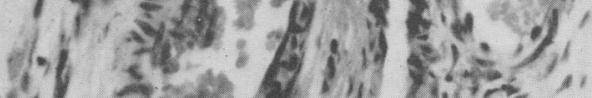
I.

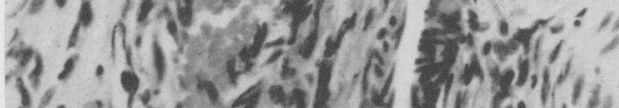
3. now

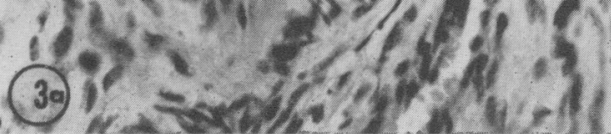

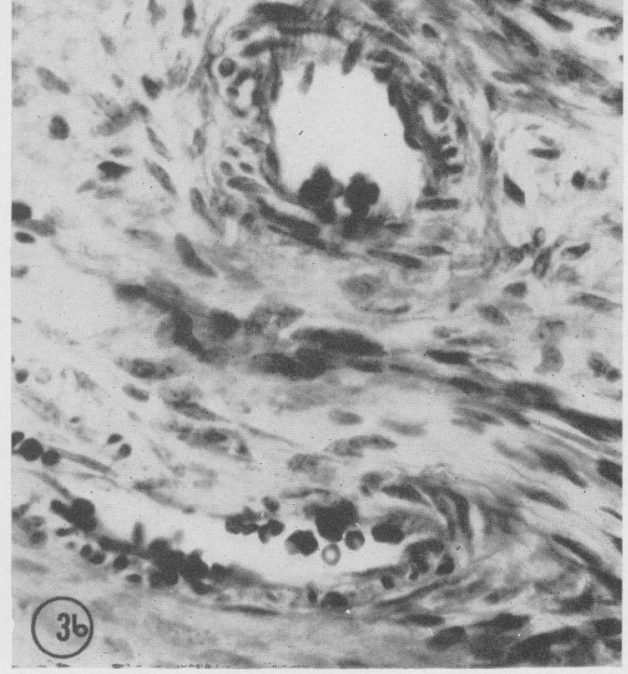

Finging f. 314 
PLAI'E 2
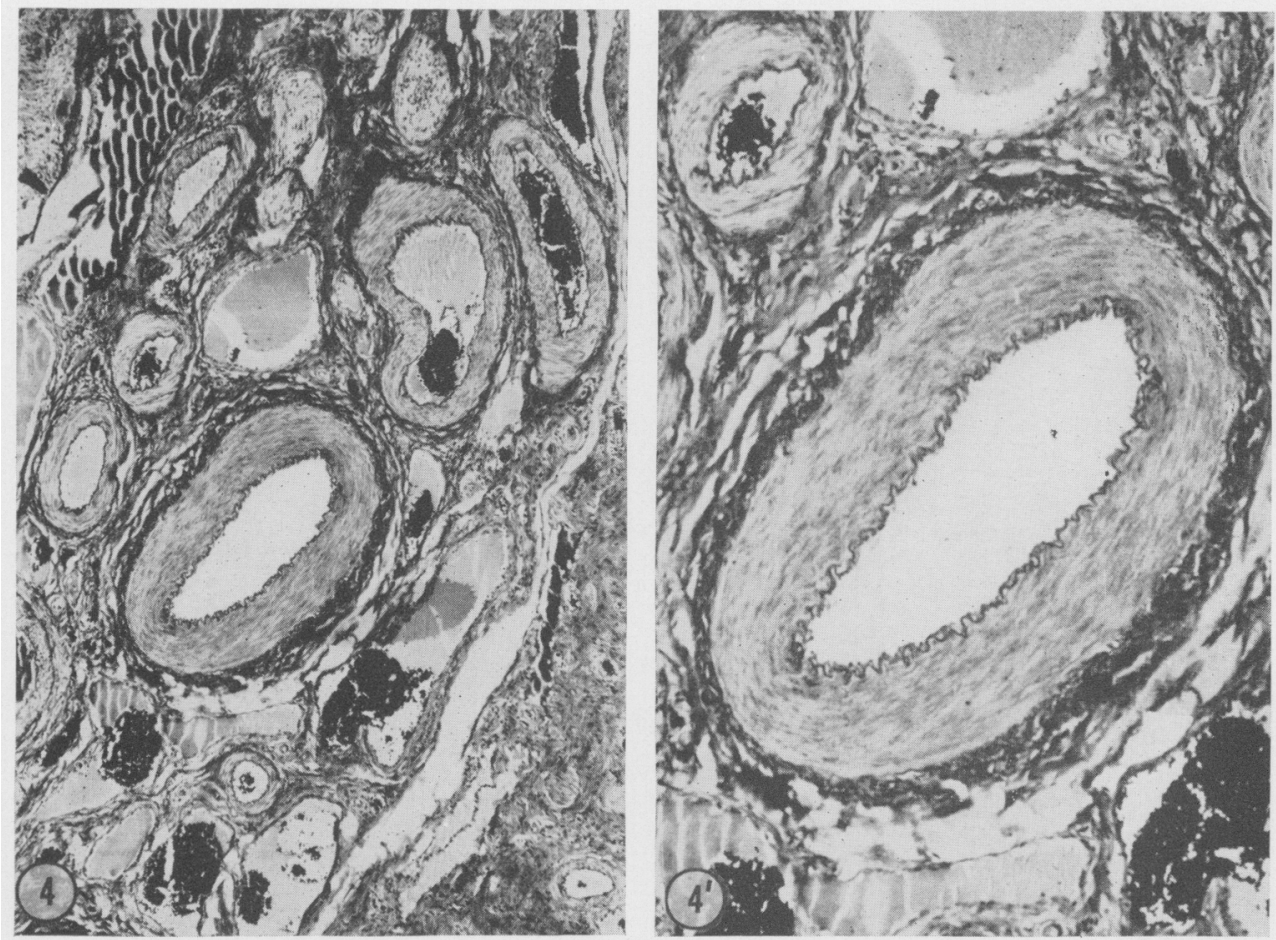

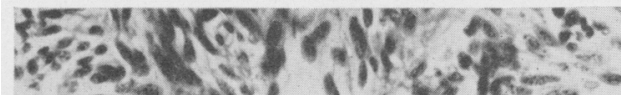

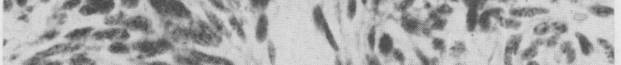

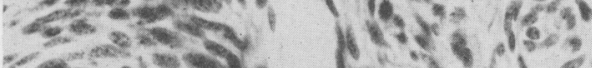

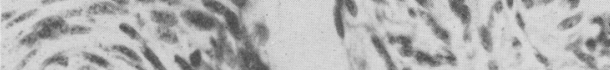

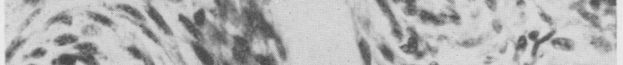

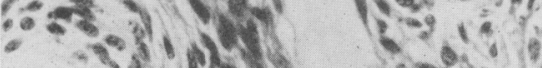

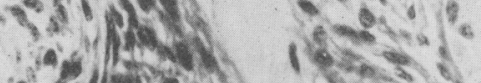

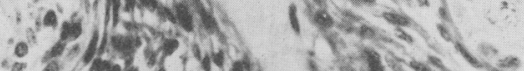
and

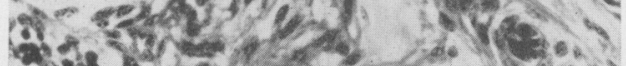

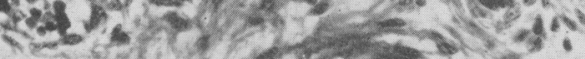

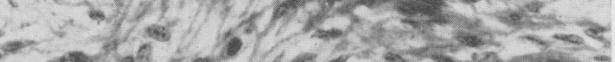

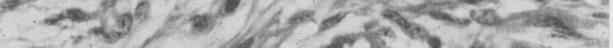

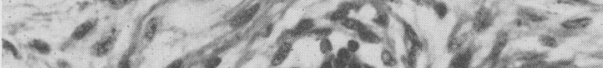
( 73 . at in $x, 0$. 2.

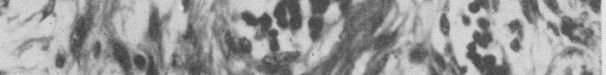

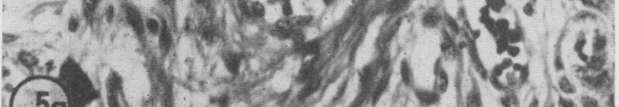
अM-20.

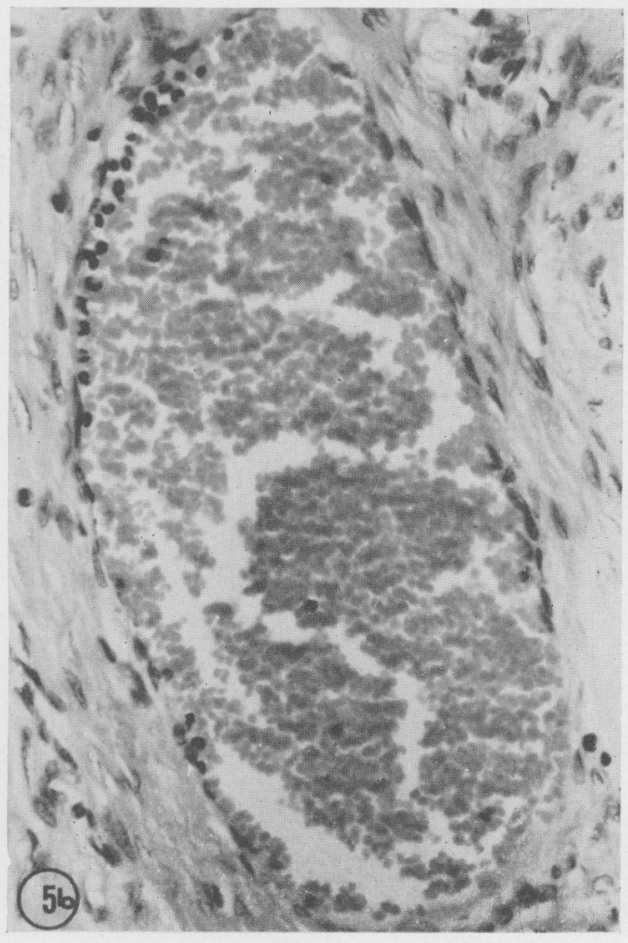


PLATE 3
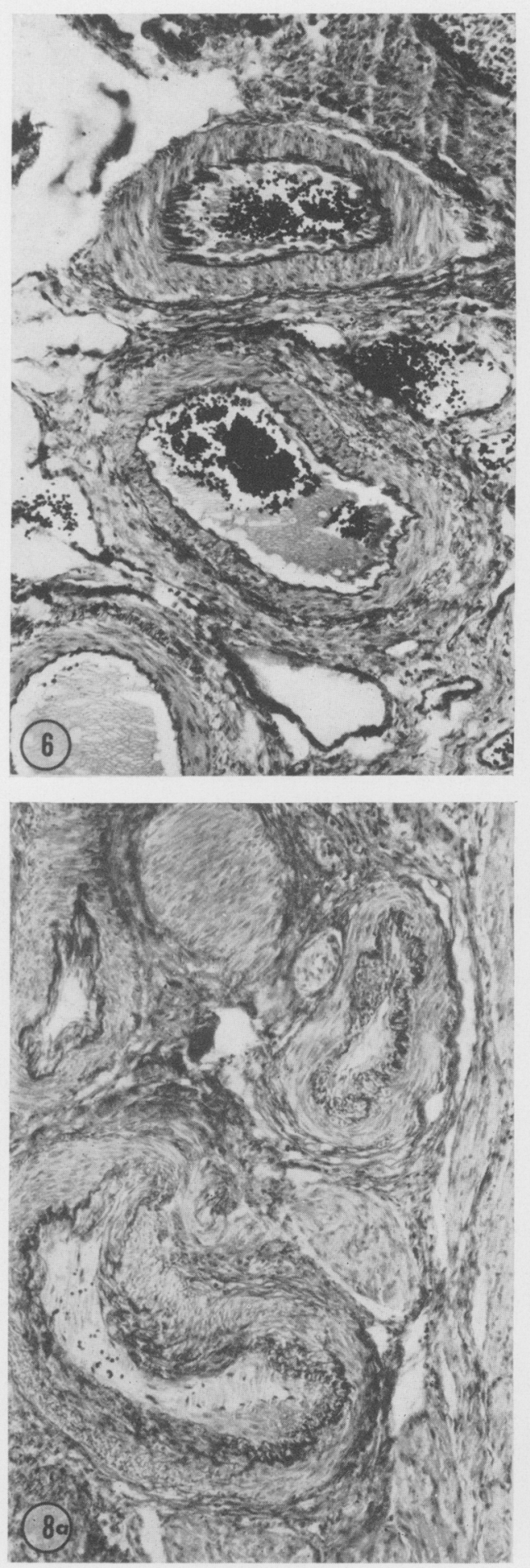

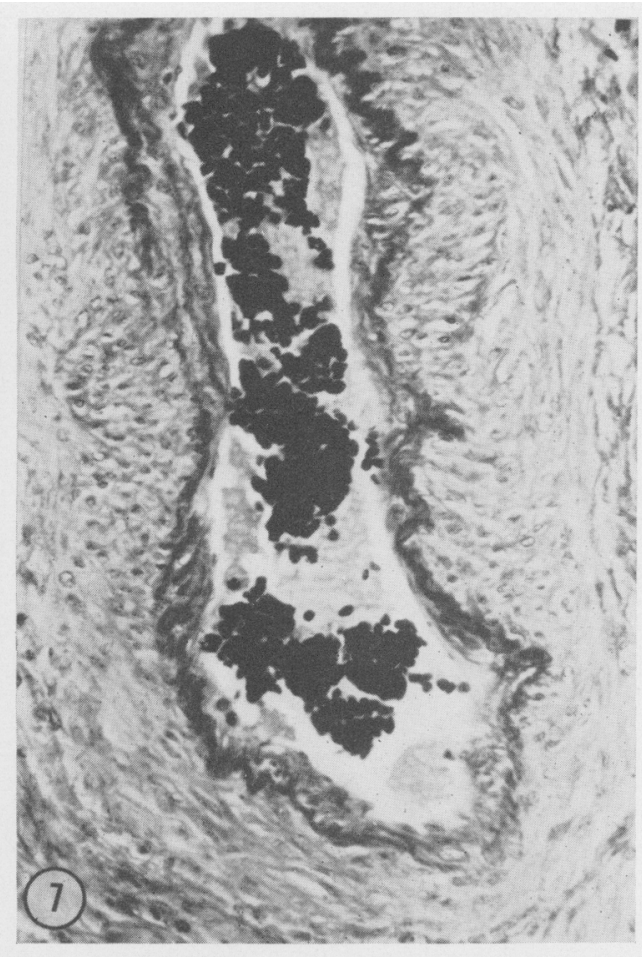

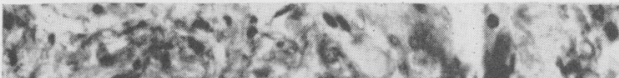

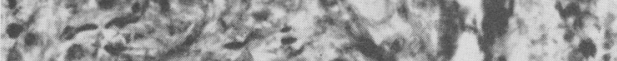
C.

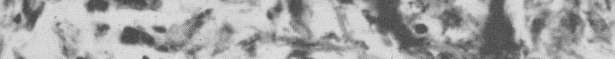

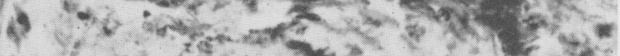

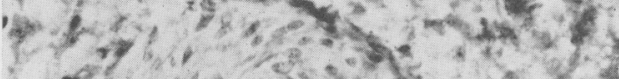

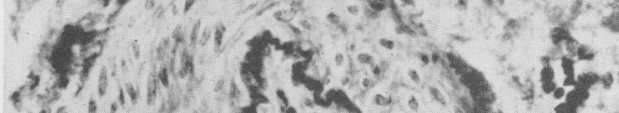

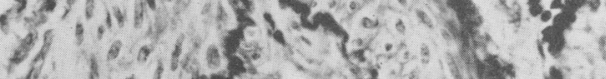

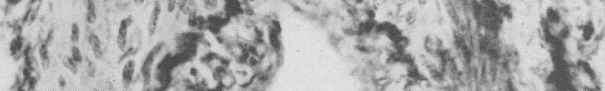

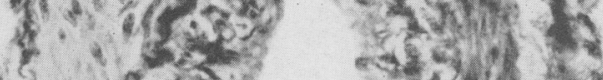

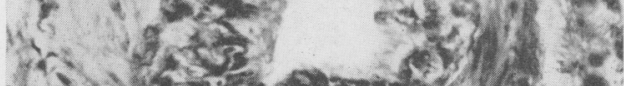

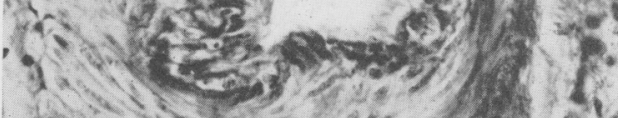

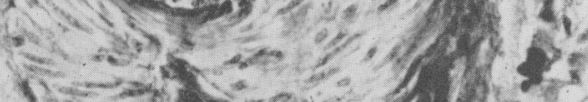

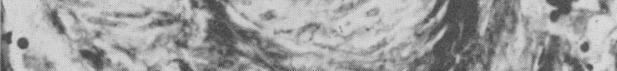

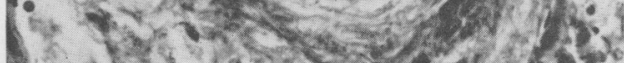

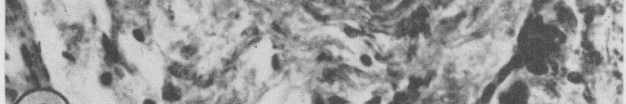

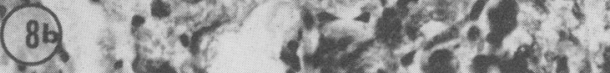



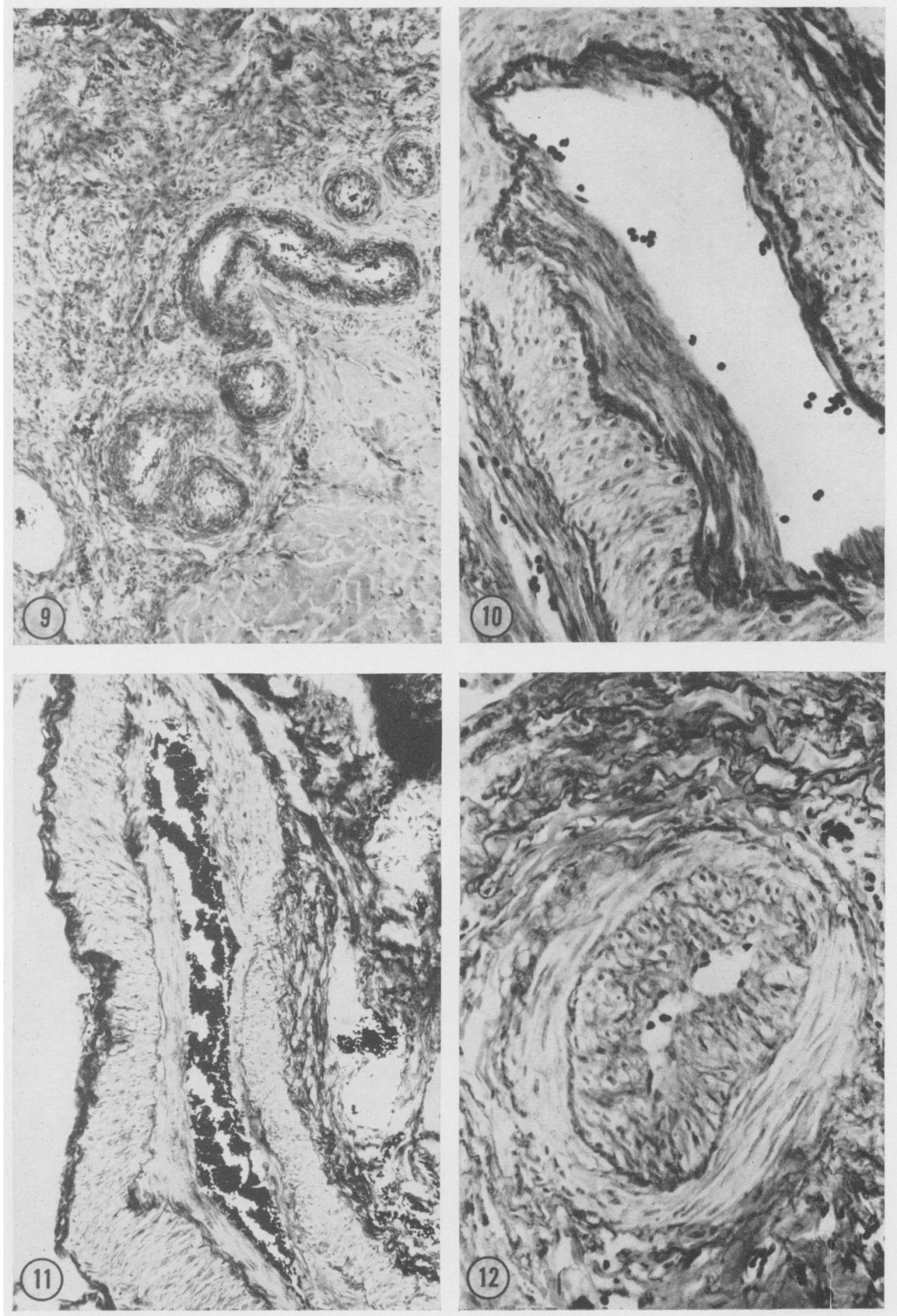
PLATE: 5
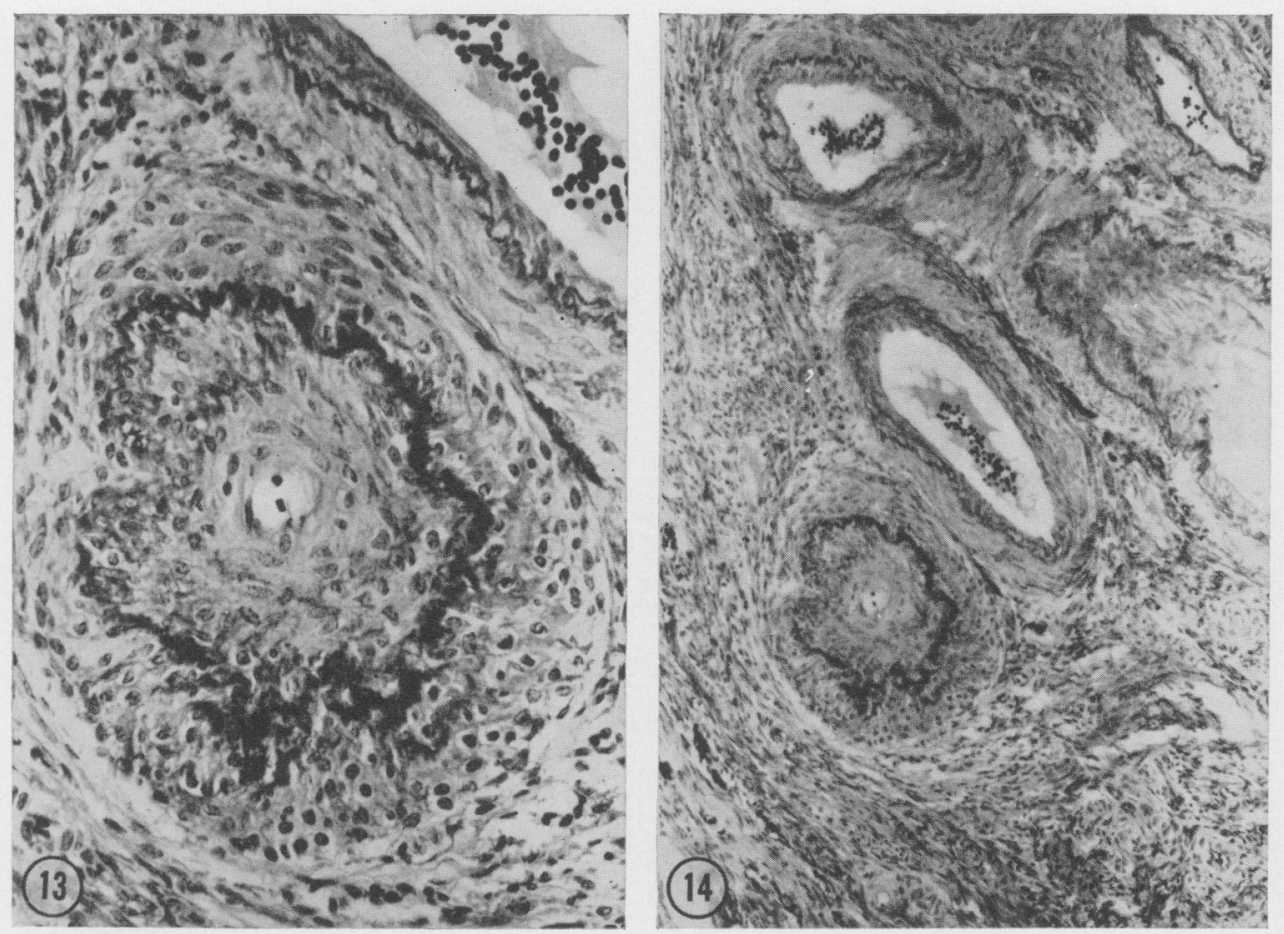
in the thickened intima than in the tunica media. In smaller arteries towards the cortex, the intimal thickening was of a uniform nature. The smooth muscle in the thickened tunica intima was arranged in a longitudinal pattern, as opposed to that in the tunica media in which the smooth muscle was in a circular pattern (Pl. 4, Fig. 12).

In the 8-year age group, the thickened intima approximated to two-thirds of the entire arterial wall in cross-sectional thickness (Pl. 4, Fig. 12; Pl. 5, Figs. 13 and 14). Collagenous tissue accumulated in the walls of the tunica media with advancing age but was present in greater amount in the thickened tunica intima. Sections stained with oil red O, according to the method of Bell (1959), did not indicate the presence of fatty substances in the thickened tunica intima nor was the presence of calcium observed, using von Kossa's stain.

\section{DISCUSSION}

In the present investigation, the arterial walls in the day-old pig were composed of one to two layers of smooth muscle cells, with a layer of internal elastic lamina. Small venous sinuses lined with endothelium, but devoid of muscle in their walls, were seen in the medulla. As in the report of Hadek \& Getty (1959), the ovary of the new-born pig presented a tri-lobed appearance macroscopically.

From the age of 1 month onwards, the walls of the ovarian arteries increased greatly in size. It appeared that rapid proliferation of the arterial wall occurred between 1 and 2 months of age. The method of smooth muscle proliferation by cell division has not so far been reported in detail. Schaffer (1922) and Evans (1923) believed that the smooth muscle cells of the tunica media of the arteries could develop from young endothelial cells. Malyschew (1929), in reporting on experiments involving the ligation of the carotid arteries in rabbits, mentioned the resemblance between endothelial cells which changed into fibroblasts and smooth muscle cells. He quoted other authors who had also suggested a transformation of endothelium into smooth muscle. In the present investigation, it was also noticed that the endothelial cells resembled the smooth muscle cells. The endothelial cells were disposed at right angles to the internal elastic lamina. In some arteries, it was observed that the endothelial cells were partly embedded in the tunica media of the arteries, giving the impression that the endothelial cells may migrate into the tunica media of the arterial wall. If endothelial cells do migrate and differentiate into smooth muscle, this phenomenon would explain the growth in thickness of the arterial wall. The present investigators are, therefore, inclined to concur with the contention of the above authors that the endothelial cells may migrate into the tunica media of the growing arteries and undergo a certain degree of metaplasia. To confirm this contention, more work should be done.

It is obvious from the results of the present studies that the arteries in the ovaries of the sow exhibit a thickening of the tunica intima with advancing age. Individual vessels varied extensively.

Buck (1958) considered that time was a particularly important variable in analysis of the human arteries, since an understanding of ageing effects provided the basis for an intelligent approach to the study of arteriosclerosis and 
atherosclerosis. This concept of the effect of age-induced changes of the arteries is also applicable in the case of the domestic pig. As age changes involve thickening of the tunica intima of the arteries, as well as alterations in other layers, the part of the arterial wall which exactly constitutes the tunica intima should be defined. However, it should be pointed out that the tunica intima of the small arterioles differs from that of the muscular and elastic arteries. Bloom \& Fawcett (1968) state that in large elastic arteries, there is not a single well defined sheet marking the junction of intima and media. Thus, in very large vessels, the tunica intima is poorly demarcated.

Bunce (1964) considered the intima to be the sub-endothelial layer between the endothelium and the internal elastic lamina and mention of a 'thick' or 'thin' intima generally refers to the relative width of the sub-endothelial layer. Gross, Epstein \& Kugel (1934) observed that the intima consisted, at birth, of a single elastic lamella (internal elastic lamina) covered with flat endothelium. With increasing age, the first change consisted of splitting of the internal elastic lamina into two membranes, between which smooth muscle fibres appeared running at times diagonally but generally in a longitudinal direction. This constituted the myo-elastic layer. The outermost of these membranes continued to demarcate the tunica intima from the tunica media and accordingly retained the name, internal elastic lamina.

In the present studies, it was seen that the internal elastic lamina was present at birth in the medullary arteries of the sow. The first signs of splitting of this elastic lamina appeared above the age of 6 months. At the age of 1 year, smooth muscle cells appeared in the tunica intima between the split layers of the elastic lamina. This was not observed in all of the vessels but occurred in only a few vessels of the cortex and medulla of the ovaries. Under the age of 6 months, however, there was no sub-endothelial layer. The endothelium, with its basement membrane, lay directly upon the internal elastic lamina. Movat, More \& Haust (1958) observed, in their studies of the human aorta, that the earliest stage of the development of the sub-endothelial layer was represented by splitting of the internal elastic lamina and the accumulation of small pools of mucopolysaccharides. Most new-born infants showed this change and between 6 months and 1 year of age, additional elastic but few collagen fibres formed in this layer. Robertson (1960) reported that smooth muscle cells in the coronary arteries and aorta continued to increase throughout childhood so that by early adulthood, a well developed tunica intima was present. Movat et al. (1958) also reported similar age related changes, but in the second decade the intima resembled a hyperplastic myo-elastic layer with irregularly arranged smooth muscle cells, histocytes, occasional fibroblasts, delicate elastic fibres and ground substance. These changes were most pronounced in the abdominal aorta. Altschul (1950) considered the fibroblasts in the intima to be endothelial cells with potential differentiating properties. From Altschul's initial observations with the light microscope and the subsequent findings by other workers with the light microscope as well as with the electron microscope, it appears that the proliferation of the tunica intima is the result of the migration of both smooth muscle cells from the media as well as the endothelial cells migrating into the intima through the fenestrations of the internal elastic lamina and the internal 
limiting membrane (elastic membrane against which lies the endothelium). According to Haust, More \& Movat (1960), the migrated endothelial cells differentiate into smooth muscle cells. Rhodin (1962) observed fine intracellular fibrils in the endothelial cells. The functions of these fibrils, although not well understood, may lend some support to the endothelial differentiation to smooth muscle. Röhlich \& Olah (1967) observed, in the endothelial cells of the arterioles of the rat myometrium, myofibril-like cross striations in the fibrils in the basal portion of the cell. In the fibril, they observed a characteristic crossstriation consisting of periodic dense bands similar to the $\mathrm{Z}$ lines of a typical myofibril.

It seems to be almost an established fact that in man, thickening of the tunica intima does take place with age in vessels such as the aorta and the coronary arteries, which have been studied quite extensively. Gottlieb \& Lalich (1954) were the first to emphasize that lesions in the aorta were common in swine and that the incidence increased with age. Among others, Skold \& Getty (1961), French et al. (1963), Getty (1965a) and Skold et al. (1966) reported the thickening of the tunica intima with advancing age in the pig. Getty $(1965 \mathrm{~b}, 1966 \mathrm{a}, \mathrm{b})$ also reported similar changes in the major vessels in the dog as well as in the hog.

So far, the study of arteriesclerosis has been made on the large arteries, such as the abdominal aorta, coronary arteries, or femoral arteries, which have been studied in a collapsed condition and not in the natural state while they are distended with blood. Bunce (1964) devised a means of obtaining the arteries distended with blood by means of a double haemostat. $\mathrm{He}$ arrived at the conclusion that intimal thickening was not as pronounced in vessels collected by this means as in the relaxed vessels. Intimal thickening, whether it is a result of the migration of smooth muscle cells or endothelial cells or both into the intima, results because the internal elastic lamina of elastic tissue permits the passage of these cells through their fenestra. Ham (1965) stated that elastic membranes were commonly fenestrated, probably because elastin was not very permeable and fenestra were required to permit the passage of nutrients and waste products through them. In the present observations, it was also noticed that the continuity of the internal elastic lamina was interrupted in most of the age groups studied.

According to Ham (1965), electron microscope studies gave no indication as to whether elastic fibres were made up of fibrils or microfibrils, instead they seemed homogeneous. Rhodin (1962) observed that the elastic fibre was represented by an amorphous material, possibly with a mucopolysaccharide matrix, similar to basement membranes. In addition, a filamentous component has been identified, although it has not been demonstrated clearly whether the filaments are distributed throughout the entire elastic fibre or only occur at the surface.

The pluripotent properties of the smooth muscle cells of the vessels have been recognized and, as such, these cells deserve a special status in the family of undifferentiated cells of mesodermal origin (Bal, 1966). Wissler (1967) has expressed the same opinion regarding the multifunctional property of these cells. Haust et al. (1960) and Pease \& Molinari (1960) recognized the ability of smooth muscle cells to form extracellular constituents, such as elastic and 
collagenous fibres and mucopolysaccharides in the intimal plaques. Buck (1962) called these cells, which were predominant in the intima of the aorta and which developed during cholesterol feeding in the rabbit, myo-intimal cells.

It appeared that the smooth muscle cells synthesized the elastic tissue which appeared in the intercellular space of the walls of the arterioles of the vascular colonies left behind by the vascular regressed corpora lutea. Yamashita (1962) calls these groups of vessels "vascular bodies" which represent the regressed corpora luta of pregnancy. He has classified these arterioles into more than fourteen types and the elastic intercellular substance into three types. It is thought that these substances, which stain like elastic fibres, may be degenerating elastic fibres.

We have observed that the smooth muscle in the wall or the tunica media of these vessels is arranged in a longitudinal pattern, therefore these vessels should have a tortuous appearance or correspond to small helicine arteries. Yamashita (1961) also observed the tortuous structure of these vessels by making neoprene latex casts. Elastic tissue was also seen in the thickened intima of some small arteries.

Due to the difficulties encountered in preservation, sectioning, and staining, the fine structure of the elastic fibre does not appear to have reached the final descriptive stage (Ham, 1965). The fenestrations in the elastic laminae have been confirmed by Pease \& Paule (1960) in their studies with the electron microscope. They observed that the fenestrations often contained extrusions of smooth muscle cytoplasm. In the small arteries of the heart and in the major coronary arteries of man, part of the endothelial cell cytoplasm may project through gaps in the elastic lamina. Collagen fibrils were also seen in the fenestra by these workers.

In the present studies, considerable progressive thickening of the tunica intima was noticed with advancing age in the arteries in the ovaries of the sow. For further manifestations of the ageing effects on such arteries, more studies need to be undertaken in animals over 8 years of age.

Regarding the structure of the veins, it was observed in the present studies that most of the venous drainage in the ovaries of the sow was by peculiar large venous sinuses lined by continuous endothelium and devoid of a muscular wall (Pl. 2, Figs. 5a, 5b). There were, however, a few veins present with walls composed of smooth muscle and elastic tissue. (Lymphatic sinuses were also similar in structure to the venous sinuses). Burr \& Davies (1951), in their studies of the vascular system of the rabbit ovary, described the largest veins in the rabbit ovary as being composed entirely of a single layer of endothelial cells. No muscle tissue or fibrous tissue was present. The walls of the veins were thickened by a thin layer of connective tissue where they emerged from the ovary. The veins of the sow's ovary, therefore, bear some resemblance to those of the rabbit's ovary.

\section{AGKNOWLEDGMENTS}

This investigation was supported in part by U.S. Public Health Service Research Grants Nos. HE-04487 and HD-00041 from the National Institutes of Health. 
This paper was taken in part from a 1966 M.S. thesis by Dr Bal under the direction of $\mathrm{Dr}$ Getty, Department of Veterinary Anatomy, Iowa State University of Science and Technology, Ames.

Sincere appreciation is extended to Dr V.C.Speer, DrV.W. Hays and Dr D.F. Cox of the Department of Animal Science, Iowa State University, for making available the hogs used in this study and to $\mathrm{Dr} \mathrm{W}$. E. Haensly for the collection of the organs and tissues. We are greatly indebted to Dr D. J. Hillmann for aid with the photomicrographs. Appreciation is also expressed for the technical assistance of $\mathbf{R}$. Aspengren and to $\mathrm{J}$. Brown for aid in the preparation of this manuscript.

\section{REFERENCES}

Attschul, R. (1950) Selected studies on arteriosclerosis. Charles C. Thomas, Springfield, Illinois.

BAL, H. S. (1966) Morphological changes in the ovaries of the sow (Sus scrofa domesticus) as infuenced by age from birth to eight years. Unpublished M.S. thesis, Iowa State University Library, Ames, Iowa.

Bell, J. T. (1959) Polyxyethylene sorbitan monopalmitato (Tween 40) as a vehicle for oil red $O$ fat stain. Stain Technol. 34, 219.

Bloom, W. \& Fawcetr, D. W. (1968) A textbook of histology, 9th edn. Saunders, Philadelphia.

Buck, R. G. (1958) The fine structure of endothelium of large arteries. F. biophys. biochem. Cytol. 4, 187.

Buck, R. C. (1962) Lesions in the rabbit aorta produced by feeding a high cholesterol diet followed by a normal diet. An electron microscope study. Br. F. exp. Path. 43, 236.

Bunce, D. F. M. (1964) Formation of the intima in arteries. Angeiologie, 16, 15.

BurR, J. H. \& Davies, J. L. (1951) The vascular system of the rabbit ovary and its relationship to ovulation. Anat. Rec. 111, 273.

Crossman, G. (1937) A modification of Mallory's connective tissue stain with a discussion of the principles involved. Anat. Rec. 69, 33.

Evans, G. (1923) The nature of arteriosclerosis. Br. med. F. i, 454.

French, J. E., Jennings, M. A., Poole, J. C. F., Robinson, D. S. \& Florey, H. (1963) Intimal changes in the arteries of ageing swine. Proc. R. Soc. B, 158, 24.

GETTY, R. (1945) The histopathology of a focal hepatitis and of its termination ("Sawdust" and "Telang" liver) in cattle. M.S. thesis, Iowa State University, Ames, Iowa.

Getry, R. (1965a) The gross and microscopic occurrence and distribution of spontaneous atherosclerosis in the arteries of swine. In: Comparative Atherosclerosis, chap. 2. Eds. J. C. Roberts and R. Straus. Hoeber Medical Division, Harper \& Row, New York.

GETTY, R. (1965b) Occurrence and distribution of spontaneous vascular lesions in the dog from birth to senescence (as compared to the hog). Gerontologist, 5, 3 (Part II), 20. (Abstr.)

Getry, R. (1966a) Gerontological studies in the dog and hog-their implications and applications. In: Adding Life to Years. Bulletin of the Institute of Gerontology, The University of Iowa, Iowa City, Iowa, 13 (4, suppl. 4$)$, 3.

GetTy, R. (1966b) Histomorphological studies in the dog and hog as related to ageing. In: Radiation and Ageing, Chap. 4, p. 245. Eds. P. J. Lindop and G. A. Sacher. Taylor \& Francis, London.

Gottlieb, H. \& Lalich, J. J. (1954) The occurrence of arteriosclerosis in the aorta of swine. Am. $\mathcal{J}$. Path. 30, 851.

Gross, L., Epstein, E: Z. \& Kugel, M. A. (1934) Histology of the coronary arteries and their branches in the human heart. Am. F. Path. 10, 253.

Hadek, R. \& Getry, R. (1959) Age change studies of the ovary of the domesticated pig. Am. J. vet. Res. 20,578 .

HaM, A. W. (1965) Histology. Lippincott, Philadelphia.

Haust, M. D., More, K. H. \& Movat, H. Z. (1960) The role of smooth muscle cells in the fibrogenesis of arteriosclerosis. Am. 7. Path. 37, 377.

Malyschew, B. F. (1929) Über die Reaktion des Endothels Arterien, carotis des Kaninchens bei doppelter Unterkindung. Virchowes Arch. path. Anat. Physiol. 272, 727.

Movat, H. Z., MORE, R. H. \& HAUST, M. D. (1958) The diffuse intimal thickening of the human aorta with aging. Am. F. Path. 34, 1023.

Pease, D. C. \& Molinari, S. (1960) Electron microscopy of muscular arteries, pial vessels of the cat and monkey. 7. Ultrastruct. Res. 3, 447.

Pease, D. C. \& Paule, W. J. (1960) Electron microscopy of elastic arteries; the thoracic aorta of rat. 7. Ultrastruct. Res. 3, 469 . 
RHodin, J. A. G. (1962) Fine structure of vascular walls in mammals with special reference to smooth muscle component. Physiol. Rev. 42, (Suppl. 5), 48.

Robertson, J. H. (1960) Stress zones in foetal arteries. F. clin. Path. 13, 133.

Röhlich, P. \& OLAh, I. (1967) Cross-striated fibrils in the endothelium of the rat myometrial arterioles. 7. Ultrastruct. Res. 18, 667.

Schaffer, J. (1922) Lehrbuch der Hisiologie und Histogenese. W. Engelmann, Leipzig, Germany. Cited by Altschul, R. (1950) In: Selected Studies on Arteriosclerosis, p. 66. Charles C. Thomas, Springfield, Illinois.

Skold, B. H. \& Getry, R. (1961) Spontaneous atherosclerosis in swine. F. Am. vet. med. Ass. 139, 655.

Skold, B. H., Getty, R. \& Ramsey, F. K. (1966) Spontaneous atherosclerosis in the arterial system of ageing swine. Am. F. vet. Res. 27, 257.

U.S. Armed Forces Instrtute of Pathology (1960) Manual of histologic and special staining technics, 2nd edn. McGraw-Hill, New York.

Wissler, R. W. (1967) The arterial medial cell, smooth muscle, or multifunctional mesenchyme? Circulation, 36, 1 .

Yamashita, T. (1961) Histological studies of the ovaries of sows. IV. Stereographical study of the vascular arrangement in the various structures of the ovaries by use of neoprene latex casting specimens. Fap. F. vet. Res. 9,31 .

Yamashita, T. (1962) Histological studies on the ovaries of sows. V. Histological observations of the various corpora lutea in the ovaries of sows which have definite histories of parturition. $\mathcal{F}_{a p}$. F. vet. Res. 10, 1 . 